\title{
UNA RÉPLICA A "LA SOCIOLOGÍA CRÍTICA DE HENRI LEFEBVRE", DE ROY ALFARO VARGAS
}

\author{
George I. García*
}

RESUMEN

\begin{abstract}
Este ensayo responde a las observaciones planteadas por Roy Alfaro Vargas en el artículo "La sociología crítica de Henri Lefebvre" respecto al libro Las sombras de la modernidad de George García.

PALABRAS CLAVE: MARXISMO * TEORÍA CRÍTICA * HENRI LEFEBVRE * IDEOLOGÍA * NEGATIVIDAD * DIALÉCTICA
\end{abstract}

ABSTRACT

This paper replies to the remarks in Roy Alfaro Vargas's article "La sociología crítica de Henri Lefebvre" regarding George García's book Las sombras de la modernidad. KEY WORDS: MARXISM * CRITICAL THEORY * HENRY LEFEBVRE * IDEOLOGY *
NEGATIVIDAD * DIALECTIC

Hace ya más de nueve años que escribí Las sombras de la modernidad (LSM, en adelante), y más de siete que este libro apareció publicado. A lo largo de estos años dicho texto ha sido comentado y criticado desde diversas perspectivas $y$ disciplinas; yo mismo, sin diferir de sus planteamientos fundamentales, he ido matizando algunas posiciones sostenidas en ese libro. Pero sobre todo, desde su gestación fue mi intención que ese libro volviera a poner en la discusión académica y política el fundamental aporte de Henri Lefebvre a la teoría crítica contemporánea.

Escuela de Filosofía y de Estudios Generales, ambas de la Universidad de Costa Rica. tuyog@hotmail.com
En este sentido, me complace que Roy Alfaro Vargas haya retomado el estudio de este importante teórico marxista en una serie de artículos en revistas académicas. Sin embargo, debo aclarar varios aspectos equívocos que plantea en su artículo La sociología crítica de Henri Lefebure ${ }^{* *}$ respecto a los planteamientos de LSM, siendo que en ese escrito no sólo realiza una lectura antojadiza de algunas tesis allí expresadas, sino que a partir de esa lectura suya llega a afirmar que ese libro abre la posibilidad de una apropiación políticamente conservadora de la producción teórica de Lefebvre.

\footnotetext{
** En Revista de Ciencias Sociales 113-114. San José. EUCR, 2006: 97-104.
} 
Empezando su artículo, Alfaro afirma que el pensamiento de Lefebvre es poco conocido en Costa Rica, en lo cual, lamentablemente, lleva razón. Pero luego, en la nota que acompaña esta afirmación, indica que "existe un trabajo de George García (2001), publicado en el país, sin embargo no va enfocado hacia lo sociológico, sino hacia lo filosófico" (Alfaro, 2006: 98). Posteriormente, reforzando este malentendido, señala que "García acentúa más la crítica de la cotidianidad que el método, lo cual implica una pérdida en el valor analítico de un discurso pretendidamente filosófico" (Alfaro, 2006: 101).

Que el discurso de LSM sea "pretendidamente filosófico" se lo saca Alfaro de su imaginación. Ninguna parte del texto indica que su enfoque "pretenda" limitarse a la disciplina de la filosofía; por el contrario, desde sus primeras páginas manifiesta su aprobación en cuanto al proyecto lefebvriano (en realidad marxiano) de trascender tanto la compartimentalización de las disciplinas académicas como la escisión entre conocimiento y activismo político (LSM: 25-26). Esta afirmación se reitera varias veces a lo largo del libro, pero a la vez está integrada en el mismo método de interpretación que el autor aplicó a los textos de Lefebvre.

Es claro que el abordaje metodológico - tema al cual se refiere una y otra vez Alfaroen este libro no es precisamente el tradicional del análisis filosófico, lo cual se evidencia al poner LSM en tensión sistemáticamente al discurso teórico de Lefebvre, en sus diferentes coyunturas, con sus condiciones históricas. El libro no trató, pues, de buscar un núcleo "filosófico" del cual habría que aislar lo "sociológico". El texto sigue, en realidad, un enfoque desde la teoría marxista, cuyas bases están en el propio Marx, a quien ciertamente no se puede ver ni como filósofo, ni como sociólogo, ni como economista, ni como historiador, etc., aunque sus planteamientos abarquen a todas esas disciplinas ${ }^{1}$.

Al respecto, cabe recordar a David Harvey, quien, consecuente con Marx y Lefebvre ${ }^{2}$, apunta que

Esta perspectiva es explicada en LSM: 22, 26, 29.

2

La reivindicación de Lefebvre de la sociología dentro del marxismo se dirigía contra aquellos
... hay que reconocer en primer lugar que toda división disciplinaria es en sí misma contrarrevolucionaria. La división del conocimiento permite a la clase política fraccionar, para mejor gobernar, en lo que refiere a la aplicación del conocimiento. Esto hace también que la comunidad universitaria se sienta impotente, porque nos conduce a pensar que sólo podemos comprender la realidad a través de una síntesis de lo que cada disciplina puede aportar a su campo de estudio particular y rápidamente nos acobardamos frente a lo que, de modo evidente, es una tarea imposible de llevar a cabo (1977: 154-155).

De igual modo, como señala Eduardo Grüner?: "filosofía, mito, tragedia, política, historia, antropología son, pues, más modos de la pregunta que preguntas diferentes, que sólo la tecnocracia del saber moderno ha podido separar ideológicamente" (2005: 18). Consideraciones del mismo tipo han sido planteadas por Karl Korsch, György Lukács, Fredric Jameson y por el propio Henri Lefebvre, entre tantos otros teóricos marxistas.

Es claro que la concepción que sigue Alfaro para desestimar a LSM como un texto con pretensiones "filosóficas" es deudataria de ese modelo burgués de saber que concibe la realidad como si estuviera compuesta por parcelas de conocimiento. A partir de allí se explica que considere que es solamente la filosofía la que debiera ocuparse de aspectos de método. LSM, por el contrario, intentaba resaltar el carácter

enfoques (tanto burgueses como del socialismo burocrático) que concebían al marxismo como una doctrina mecanicista en la cual todo lo social era mero reflejo de las estructuras económicas. Sin embargo, Lefebvre nunca limitó sus enfoques a la sociología, la cual era un campo de estudio que en su concepción no desterraba las consideraciones de carácter estético o político, por ejemplo.

3 Dicho sea de paso, Alfaro le atribuye a Jameson, en la nota 20 de su artículo, una argumentación que, si bien hubiera podido ser suscrita por el marxista norteamericano, es parte del prefacio que Grüner le dedica a los ensayos de Jameson y Žižek. 
totalizante de la reflexión lefebvriana, por lo cual no es un trabajo ni filosófico ni sociológico en sentido estricto; sí "pretendía" ser un libro marxista, y su método fue en ello consecuente.

Pero, prosigue el artículo: "García, más allá de plantearse la reflexión filosófica sobre el método (la negatividad) y su estrechamente interrelacionado concepto de ideología; se enfrasca en el análisis de la relación cotidianidad-modernidad" (Alfaro, 2006: 101). Resulta curioso que a un libro cuyo título sea Las sombras de la modernidad, y cuyo subtítulo sea La crítica de Henri Lefebvre a la cotidianidad moderna se le reclame "enfrascarse" "en el análisis de la relación cotidianidad-modernidad" - su tema - en lugar de dedicarse a otros menesteres.

De estas afirmaciones se colegiría que Alfaro hubiera esperado que un "pretendido" filósofo ("García") escribiera un tratado sobre el método en Henri Lefebvre, cosa que en ningún momento fue el tema de esa investigación. Ello no significa que las consideraciones sobre el método en Lefebvre se hallen ausentes; se encuentran a lo largo de todo el libro, $y$, de hecho, la periodización propuesta por LSM muestra los cambios que durante alrededor de más de cuarenta años sufrió ese método. Quien lea El materialismo dialéctico, de 1939, y La presencia y la ausencia, de 1980, puede observar cómo la dialéctica de Lefebvre no fue un método inmutable, como sugiere el artículo de Alfaro (de un modo idealista) al no diferenciar entre distintas coyunturas de la conceptualización lefebvriana, sino varios métodos dialécticos, históricamente situados, de aprehensión de la realidad. ¿Cómo se explican esos cambios? Por factores de la historia intelectual, pero en última instancia siempre por la historia, esto es, por la lucha de clases que dinamiza el cambio social.

Cada coyuntura de la teorización de Lefebvre sobre la cotidianidad (el tema del libro) es analizado en relación con el contexto histórico en el que aparece la producción teórica del marxista francés, y cada uno de los capítulos 2,3 y 4 se refieren a las implicaciones sociohistóricas de las formulaciones lefebvrianas. El análisis conceptual inmanente de las tesis lefebvrianas aparece referido tanto a la historia social como a los movimientos estéticos e intelectuales de cada coyuntura. El cambio social, producto de la negatividad, es uno de los criterios rectores del texto.

En cuanto a la negatividad misma, es irónico que el crítico del texto no haya notado que en la tradición marxista, la crítica es precisamente una aplicación de la negatividad. Este carácter crítico (negativo) de la teorización lefebvriana se encuentra desde el título del libro, y forma parte fundamental de su argumentación. Las alusiones al carácter negativo de la dialéctica de Lefebvre son parte fundante de la interpretación en LSM sobre las teorías lefebvrianas de lo cotidiano. Posiblemente Alfaro hubiera preferido que el texto reiterara compulsivamente el término "negatividad" a modo de eslogan publicitario, pero si lo busca como concepto lo hallará a lo largo del libro: está presente cada vez que hay alusión a categorías que se implican necesariamente en la teoría lefebvriana, como dialéctica, contradicción, o transducción (que Lefebvre utiliza sobre todo en los años sesentas). Me queda la duda, pues, sobre cómo LSM ha "solapado el eje de dinamización del contenido" (Alfaro, 2006: 101).

Más aún, el carácter negativo de la dialéctica de Lefebvre se indica y se muestra una $y$ otra vez siguiendo el hilo conductor de su crítica a la cotidianidad, $y$ no se limita a las dos páginas (33 y 71) en las que Alfaro afirma que el autor del libro "indica muy brevemente" el carácter negativo de la dialéctica de Lefebvre. Dejando de lado los numerosos movimientos dialécticos que el libro presenta respecto a las argumentaciones lefebvrianas, me quedan algunas otras dudas sobre esta crítica: ¿No vincula el libro explícitamente a Lefebvre con dadá (LSM, 34) y Nietzsche (LSM, 39) precisamente por el tema de la negación? ¿Qué sucede, por ejemplo, con la página 136, donde se relaciona a Lefebvre con Adorno y Horkheimer por su común pensamiento negativo? ¿No se extiende la aclaración sobre las diferencias entre la negatividad en Lefebvre y en Adorno en la página 104? ¿Señala o no el libro en página 189 que la dialéctica de Lefebvre se diferencia de la de Agnes Heller por el mayor énfasis de esta sobre la positividad? ¿No se contrasta en la 195 a Lefebvre respecto a Berger y Luckmann 
precisamente por la preocupación del marxista francés por los aspectos negativos (en sentido dialéctico) del orden social? Y, contra las críticas de Castells, ¿no defiende LSM a la dialéctica de Lefebvre en estos términos: "la cientificidad como ideología [énfasis de esta réplica] que relega las categorías de pensamiento que no comparte al ámbito de la filosofía o la religión (i!!). La positividad que condena a su contraria, la negación... esto es precisamente pensamiento unidimensional arropado bajo lenguaje marxista" (LSM, 143)?

Pero posiblemente la arbitrariedad de la lectura (i?) de Alfaro se muestra del modo más prístino al reclamarle a un libro al que pretende "caracterizar críticamente" (Alfaro, 2006: 98) que haya "desestimado el alcance y la validez, así como la importancia del concepto de ideología en esta sociología crítica" (Alfaro, 2006: 101). En el aparato crítico de LSM la categoría de ideología es incluso más importante que para el propio Lefebvre, quien al analizar prácticas sociales prefirió referirse a categorías como alienación, fetichismo y mistificación, subordinando la de ideología ${ }^{4}$, debido a que aquellas se refieren más directamente a tipos de praxis invertidas, y no estrictamente a discursos legitimadores.

Como la importancia de la categoría de ideología - junto con la de alienación y la de negatividad, a pesar del dictamen del reseñador- es tan obvia, central y fundamental en la interpretación que LSM presenta respecto a las teorías lefeburianas de lo cotidiano, remito al lector interesado a que se cerciore por sí mismo. Sin intención de exhaustividad, enumero algunas páginas en las que LSM trabaja (no simplemente "indica") sobre el concepto de ideología y términos afines (ideología, ideologema, ideológicamente, ideologizar): 22,

De allí que tampoco sea correcto afirmar, como lo hace Alfaro (2006: 97), que "la sociología crítica lefebvriana se estructura alrededor de su concepto de ideología”, aunque sin duda la categoría de ideología sea parte irrenunciable de la producción teórica de Lefebvre y del marxismo. La problemática de la ideología se desplazó, a nivel de los análisis sociales concretos de Lefebvre, hacia las prácticas -no solamente discursivas- reproductoras de relaciones asimétricas de poder.
$48,52,61,76,77,80,82,86,93,119,121,131$, $140,141,143,148,151,153,158,159,167,179$, 208 (el libro tiene 212 páginas de desarrollo temático).

Para coronar sus afirmaciones sobre el modesto libro que aquí defiendo, Alfaro (2006: 101) incluye al autor de LSM en el conservadurismo posmoderno: "esta pérdida de los diversos autores, en relación con el término de ideología y el de negatividad, más que una debilidad de ellos, es una manifestación de un contexto que acentúa peyorativamente el concepto de ideología. No obstante, este 'olvido' puede permitir una reabsorción de Lefebvre, dentro del conservadurismo posmoderno"s.

Aquí, el autor del artículo intenta una lectura ideológica sin antes haber hecho una lectura literal de LSM (ninguna hermenéutica justifica tantos yerros de lectura; ¿será algún artilugio de lectura posmoderna por parte de Alfaro?). Se le agradece que afirme que esa supuesta pérdida de los "términos" (categorías, en realidad, lo cual es muy diferente) de ideo$\log ^{6}{ }^{6} y$ negatividad no sea tanto una debilidad de los comentaristas reseñados, pero, en el caso de LSM, creo que ha quedado claro que no ha habido "olvido" alguno respecto de esas categorías (no "términos"), por lo cual es absurdo que Alfaro incluya a este "comentarista" entre aquellos que permiten esa presunta cooptación ideológica conservadora.

Por lo demás, en LSM no existe ni la más leve insinuación de que las teorías de Lefebvre

5

Como en su artículo Alfaro no se refiere a los textos que "caracteriza críticamente", sino a "autores" y "comentaristas" que han "desestimado" u "olvidado" el concepto de ideología, remito al lector a otros dos textos por los cuales, entre otros, podría formarse un criterio sobre la valoración de la categoría de ideología por parte de quien escribe estas líneas. Cfr. García, George I. (2002 y 2007).

6 Pero, concedamos, empero, que LSM no incorporara la categoría de ideología en su aparato hermenéutico: ¿será que Marx, al abandonar gradualmente la categoría de ideología en favor de la de fetichismo, "olvidó" la crítica revolucionaria? Entonces, según la lógica de Roy Alfaro, Marx mismo permitió la absorción de El capital dentro del conservadurismo posmoderno. 
puedan ser integradas por la posmodernidad: a lo largo del libro se enfatiza que estas son parte del movimiento teórico más fructífero del marxismo; consecuentemente, se desarrollan críticamente las categorías -en absoluto posmodernas- de modo de producción, lucha de clases, alienación, etc., a la vez que se insiste sobre el carácter transformador de la teoría. Incluso el texto recupera el respeto de Lefebvre por Lenin (LSM, 212), quien no es, que yo sepa, santo de la devoción del "conservadurismo posmoderno". En esta misma página, la última de las conclusiones del libro, aparece un contraste entre la crítica lefebvriana de la vida cotidiana $y$ "los discursos nihilistas de esta época supuestamente posmoderna" (LSM, 212) y un rechazo de estos últimos, en nombre del proyecto marxista de transformación revolucionaria del capitalismo (otra categoría que desde parámetros posmodernos es usualmente desechada por su supuesto "esencialismo").

Finalmente, me refiero a otra frase curiosa del artículo de marras, referida a LSM: "el texto parece una apología contra los detractores del marxismo, envuelto en el clamor de un marxismo aún vivente". Me parecería un poco exótico que la propuesta de politización de lo cotidiano que se defiende en ese libro vaya dirigida a "los detractores del marxismo", como si los argumentos de LSM hubieran querido convencer a tal público (¿Thelmo Vargas? ¿Óscar Arias?) de pasarse a las filas del socialismo científico.

En todo caso, como bien sabría quien conozca los rudimentos de una hermenéutica marxista, un discurso se comprende históricamente, lo cual implica tomar en cuenta el contexto de su enunciación. Alfaro no recuerda que en Costa Rica durante los años noventa - cuando este texto fue redactado - el marxismo había caído en el descrédito, merced a la deserción de sus filas de gran cantidad de intelectuales, y a una campaña ideológica bastante exitosa, según la cual después de la caída del socialismo histórico no habían alternativas frente al capitalismo. Más allá de lo que pensaran "los detractores del marxismo", LSM presentó la teoría lefebvriana como una opción vigente de análisis social marxista frente al posestructuralismo, situando la problemática de lo cotidiano como campo de lucha desde lo político. El "clamor de un marxismo aún viviente" fue, precisamente, lo que inspiró LSM, en un período anterior a las movilizaciones contra el "Combo" del ICE y la campaña contra el TLC. De allí que, incluso cediéndole a Alfaro que el tono de ese libro fuera el de una "apología" —opinión infundada, y que cualquier lector de ese texto puede valorar por sí mismo-, la coyuntura del libro hubiera justificado una defensa de la matriz teórica marxista ${ }^{7}$.

Como consideración final, espero haber dejado en claro que en el artículo al cual me he referido aquí Roy Alfaro ha desfigurado, merced a una lectura que cuando menos debe ser calificada de negligente, un libro cuyas falencias no se encuentran, en absoluto, allí donde el "crítico" las ha señalado. Henri Lefebvre es un autor sumamente valioso para el pensamiento crítico actual, un insumo ineludible para pensar nuestro mundo contemporáneo. En Costa Rica no lo descubrió George García, y ciertamente Roy Alfaro no dice nada nuevo cuando indica la importancia que para la teoría social crítica tienen las categorías de ideología y de negatividad. Sorprende, pues, que este pretenda mostrarse como un innovador a costa de tergiversar hasta lo irreconocible a un libro al cual parece sólo poder criticar reclamándole cuestiones inatinentes o afirmando que no plantea elementos que cualquier lector puede encontrar allí debidamente desarrollados.

\section{REFERENCIAS}

Alfaro Vargas, Roy. "La sociología crítica de Henri Lefebvre”. Revista de Ciencias Sociales 113-114. Editorial Universidad de Costa Rica. 2006: 97-104.

García, George I. Las sombras de la modernidad. La crítica de Henri Lefebure a la cotidianidad moderna. San José: Arlekín, 2001.

$7 \quad$ La oscura redacción de este párrafo, así como la vaguedad de la nota número 22 en él, impiden comprender qué sentido tiene su mención de Helio Gallardo. 
- "Utopía e ideología. Kandinsky y la modernización del espacio pictórico". Kánina. Revista de Artes y Letras XxVI (2), julio-diciembre. Editorial Universidad de Costa Rica. 2002: 135-145.

"Ideología de lo público y ética de la política". Rovira Mas, Jorge (ed.). Desafíos políticos de la Costa Rica actual. San José: EUCR, 2007.
Grüner, Eduardo. La cosa política, o el acecho de lo Real. Buenos Aires: Paidós, 2005.

Harvey, David. Urbanismo y desigualdad social. México: Siglo XXI, 1977.

Žižek, Slavoj. "El espectro de la ideología". En: Žižek, S. (comp.). Ideología. Un mapa de la cuestión. Bs. Aires: Fondo de Cultura, 2003. 